Tropical Journal of Pharmaceutical Research January 2016; 15 (1): 183-188

ISSN: $1596-5996$ (print); 1596-9827 (electronic) (c) Pharmacotherapy Group, Faculty of Pharmacy, University of Benin, Benin City, 300001 Nigeria.

All rights reserved.

Available online at http://www.tjpr.org

Original Research Article

http://dx.doi.org/10.4314/tjpr.v15i1.25

\title{
Determination of Synthetic Food Colors, Caffeine, Sodium Benzoate and Potassium Sorbate in Sports Drinks
}

Fatemeh Zamani Mazdeh ${ }^{1}$, Zeinab Moradi ${ }^{1}$, Ghazaleh Moghaddam ${ }^{1}$, Zhila $^{2}$
Moradi-Khatoonabadi ${ }^{1}$, Farideh Esmaeili Aftabdari ${ }^{1}$, Parnaz Badaei ${ }^{2}$ and
Mannan Hajimahmoodi ${ }^{1,2 \star}$
${ }^{1}$ Food and Drug Administration, ${ }^{2}$ Department of Drug and Food Control, Faculty of Pharmacy, Tehran University of Medical ${ }^{1}$ Food and Drug Administt
Sciences, Tehran, Iran

${ }^{\star}$ For correspondence: Email:

Received: 26 February 2015

Revised accepted: 11 November 2015

\begin{abstract}
Purpose: To employ high performance liquid chromatography (HPLC) techniques to determine edible additives in commercial sports drinks.

Methods: A total of 105 samples including 21 different brands of sports drinks were purchased from markets in Tehran, Iran. The process conditions included a C18 column, a mobile phase consisting of aqueous ammonium acetate buffer $(\mathrm{pH}=4.2)$ and acetonitrile $(80: 20 \mathrm{v} / \mathrm{v})$ at a flow rate of $0.8 \mathrm{ml} \mathrm{min}{ }^{-1}$. The injection volume was $20 \mu \mathrm{L}$ and the UV detector was set at $225 \mathrm{~nm}$.

Results: Mean recovery was between 95 and $106 \%$. The mean concentrations of sodium benzoate and potassium sorbate in Iranian brands (147.72 and $11.54 \mathrm{ppm}$, respectively) were significantly higher than in foreign brands (19.43 and $4.91 \mathrm{ppm}$, respectively, $p<0.05$ ). The maximum amount of sodium benzoate and potassium sorbate was $251.50 \pm 18.69$ and $96.38 \pm 38.56$ ppm, respectively, while caffeine content was in the range of $293.48 \pm 14.33-607.32 \pm 135.33 \mathrm{ppm}$.

Conclusion: HPLC permits the detection of sodium benzoate and potassium sorbate at very low concentrations. Furthermore, caffeine was detected in all the sport drinks. Only Brilliant Blue and Allura Red were detected in the drinks.
\end{abstract}

Keywords: Edible additives, Sports drinks, Sodium benzoate, Potassium sorbate, Caffeine, Brilliant Blue, Allura Red

Tropical Journal of Pharmaceutical Research is indexed by Science Citation Index (SciSearch), Scopus, International Pharmaceutical Abstract, Chemical Abstracts, Embase, Index Copernicus, EBSCO, African Index Medicus, JournalSeek, Journal Citation Reports/Science Edition, Directory of Open Access Journals (DOAJ), African Journal Online, Bioline International, Open-J-Gate and Pharmacy Abstracts

\section{INTRODUCTION}

Recently, sport drinks have gained popularity based on the attribution of energy-giving properties. Caffeine which is almost certainly the most widely consumed psychoactive substance in the world is a well-known stimulant effect over the central nervous system [1]. The US Food and drug Administration (FDA) limits the maximum amount in carbonated beverages to $6 \mathrm{mg} / \mathrm{oz}$. [2]. On the other hand, preservatives are permitted as additives in energy and sport drinks [3-5]. Benzoic acid is sodium salt of benzene carboxylic acid and phenilcarboxylic acid, is 180 times more soluble than benzoic acid in water $[6,7]$. The additives may also cause allergic reactions in sensitive individuals as well as hyperactivity color. However, potassium solubility is more than $50 \%$ in foods [6]. In Europe sorbates and benzoates are permitted in beverages [8]. 
For safety reasons, there have been recent reductions in the number of permitted food colors but because of their low price, effectiveness and stability they are still being used [9-11]. The lists of permitted food colors is definitely different between countries [12]. The beverage processing industry uses several types of food colors, but to minimize potential toxicity, the amounts of permitted synthetic colors used are strictly limited $[11,13]$. So they are permitted and frequently used in EU countries. However, they are not permitted in other countries, including Japan and USA [14].

The main objectives of this work were to evaluate the levels of mentioned additives compounds in 105 sport drinks and by comparing the levels of these compounds with the current available standards.

\section{EXPERIMENTAL}

A total number of 105 samples were purchased in accordance with the market availability, in Tehran - Iran. The samples were collected between December, 2013 and January. 2014. The studied commodities were 21 different brands of sports drinks. All stages of the experiment were done before expiry date of the drinks. The analyses were carried out in triplicate for each sample.

\section{Standards and chemicals}

All solvents/chemicals used were of analytical grade. In the study, high purity standards of potassium sorbate (>99\%), sodium benzoate (> $99 \%$ ), sodium salicylate (> $99.5 \%$ ), Caffeine (> $99 \%)$, ammonium acetate (98\%), acetic acid glacial $(100 \%)$ and HPLC - grade acetonitrile were purchased from Merck (Darmstadt, Germany). Deionised water was prepared by a Branstead Easypure II system (Thermo Fisher Scientific Inc., Waltham, MA, USA). Methanol (Merck) was HPLC quality. Acetic acid (Merck, d $=1.05$ ) that was used for acetate buffer and $\mathrm{NaOH}$ (Merck, $5 \mathrm{~mol} / \mathrm{L}$ ) that was used for regulating $\mathrm{pH}$ were of analytical purity. Millipore Milli - $Q$ water was used in all stages of the assay.

\section{Chromatographic conditions}

Sport drinks were filtered through $0.45 \mu \mathrm{m}$ membrane filter and ultrasonicated, before HPLC analysis. Analytical separation of the caffeine, sodium benzoate and potassium sorbate was carried out by reverse phase liquid chromatography of an Agilent 1200 series liquid chromatograph equipped with a gradient pump capable of mixing four solvents, a vacuum membrane degasser, a $20 \mu \mathrm{L}$ loop injector and a UV Detector (Agilent Technologies, Santa Clara, CA, USA). Analysis was performed on an Eclipse - XDB C18 column $(150 \times 4.6 \mathrm{~mm}, 5 \mu \mathrm{m})$. The mobile phase consisted of an aqueous ammonium acetate buffer $(\mathrm{pH}=4.2)$ and acetonitrile $(80: 20 \mathrm{v} / \mathrm{v})$ with a flow rate of $0.8 \mathrm{ml}$ $\min -1$. The injection volume was $20 \mu \mathrm{L}$ and the UV detector was set at $225 \mathrm{~nm}$. The chromatographic system was initially conditioned by the mobile phase until a stable baseline signal was obtained, which needed at least $1 \mathrm{~h}$.

To evaluate the synthetic colors, the mobile phase consisted of ammonium acetate solution (0.1 mol L-1, pH = 6.7), as solvent $\mathrm{A}$ and methanol - acetonitrile $(50: 50, \mathrm{v} / \mathrm{v})$, as solvent $B$. A cellulose membrane with a pore diameter 0.45 $\mu \mathrm{m}$ was used to filter mobile phase A. In order to achieve a successful resolution, gradient elution programs were tested and the flow rate was always kept constant at $1 \mathrm{ml} \mathrm{min}-1$. The final optimized gradient program was $3 \%$ solvent B as the initial step; then it increased linearly to 60 $\%$ in $18 \mathrm{~min}$ and was held for $2 \mathrm{~min}$. Analysis was performed on the UV detector with two optimized conditions. First, the fixed wavelength was set at $250 \mathrm{~nm}$ within the whole runtime to make it easy to use for amateur operators; next, it was programmed at $415 \mathrm{~nm}$ for tartrazine, 460 $\mathrm{nm}$ for Quinoline yellow, Ponceau 4R, and Sunset yellow, $500 \mathrm{~nm}$ for Allura red $A C$ and Carmosine, and $600 \mathrm{~nm}$ for Indigo carmin and Brilliant blue for different colorants [11].

\section{Data analysis}

All measurements were replicated three times to improve the reliability of the results. Data were analysed using statistical program for social sciences (SPSS), version 21 (IBM SPSS Inc., Chicago, USA), Data are expressed as mean \pm SD. One way analysis of variances (ANOVA Dunnett T3) was used for determining significant difference which was set at $p<0.05$.

\section{Method validation}

The LOD and the LOQ were calculated as LOD = $3.3 \sigma / S$ and $L O Q=10 \sigma / S$, where $\sigma$ is the standard deviation of the response and $S$ is the slope of the calibration curve. The estimate of $\sigma$ was carried out by analyzing blank samples seven times, measuring of the magnitude of the analytical background response and then calculating the standard deviation of the response. Recoveries were determined by spiking a sport drink known to be free of all 
additives, in triplicate, with known amounts of studied additives at final concentrations between.

\section{RESULTS}

The analytical methodology revealed good linearity, sensitivity, exactitude and precision. Correlation coefficients $\left(r^{2}\right)$ were comprised between 0.998 for caffeine acid and 0.999 for the other studied factors. Limits of qualification and quantification are presented in Table 1 respectively.

Recovery values were between $95 \%$ and $106 \%$ for studied additives at determined spiked levels. The developed method was successfully in the evaluation of the mentioned additives. Figure 1 shows the chromatograms of a standard solution containing sodium benzoate, potassium sorbate and also caffeine, while in Figure 2 the synthetic dyes resolution are illustrated.

The concentrations of preservatives quantified from sports- drink samples are shown in Table 2. Sodium benzoate was found in 14 brands at levels ranging between 12.50 and 251.50 ppm, (Table 2).

Moreover, 15 brands didn't have any potassium sorbate. The levels of sodium benzoate and potassium sorbate in Iranian brands (147.72 and 11.54 ppm, respectively) were significantly more than foreign studied brands (19.43 and 4.91 ppm respectively).

Also, methods to evaluate levels of coloring in foods for quality control are currently made by the TLC method. The mean concentration of colors in each sample group is presented in Table 3.

Table 1: Recovery data for the additives in sports drinks

\begin{tabular}{lccccc}
\hline Additive & Calibration Data & $\mathbf{R}^{2}$ & LOD $(\mathbf{p p m})$ & LOQ $(\mathbf{p p m})$ & Recovery $(\%)$ \\
\hline Sodium benzoate & $\mathrm{y}=121.3 x-56.82$ & 0.999 & 0.6413 & 1.9435 & $99-102$ \\
Potassium sorbate & $\mathrm{y}=69.61 \mathrm{x}+36.64$ & 0.999 & 1.1224 & 3.4013 & $98-100$ \\
Caffein & $\mathrm{y}=39.31 \mathrm{x}+9.87$ & 0.998 & 1.8263 & 5.5344 & $97-101$ \\
Quinoline Yellow & $\mathrm{y}=38.71 \mathrm{x}-6.952$ & 0.999 & 0.465 & 1.409 & $96-105$ \\
Sunset Yellow & $\mathrm{y}=47.20 \mathrm{x}-13.56$ & 0.999 & 0.357 & 1.082 & $98-106$ \\
Carmoisine & $\mathrm{y}=62.40 \mathrm{x}-16.47$ & 0.999 & 0.666 & 2.019 & $95-105$ \\
Ponceau 4R & $\mathrm{y}=21.98 \mathrm{x}-6.095$ & 0.999 & 0.873 & 2.646 & $97-103$ \\
Allura Red & $\mathrm{y}=70.08 \mathrm{x}-10.09$ & 0.999 & 0.510 & 1.547 & $95-102$ \\
Indigotine & $\mathrm{y}=56.71 \mathrm{x}-12.95$ & 0.999 & 0.431 & 1.307 & $99-101$ \\
Brilliant Blue & $\mathrm{y}=100.2 \mathrm{x}-19.83$ & 0.999 & 0.562 & 1.704 & $95-100$ \\
\hline
\end{tabular}

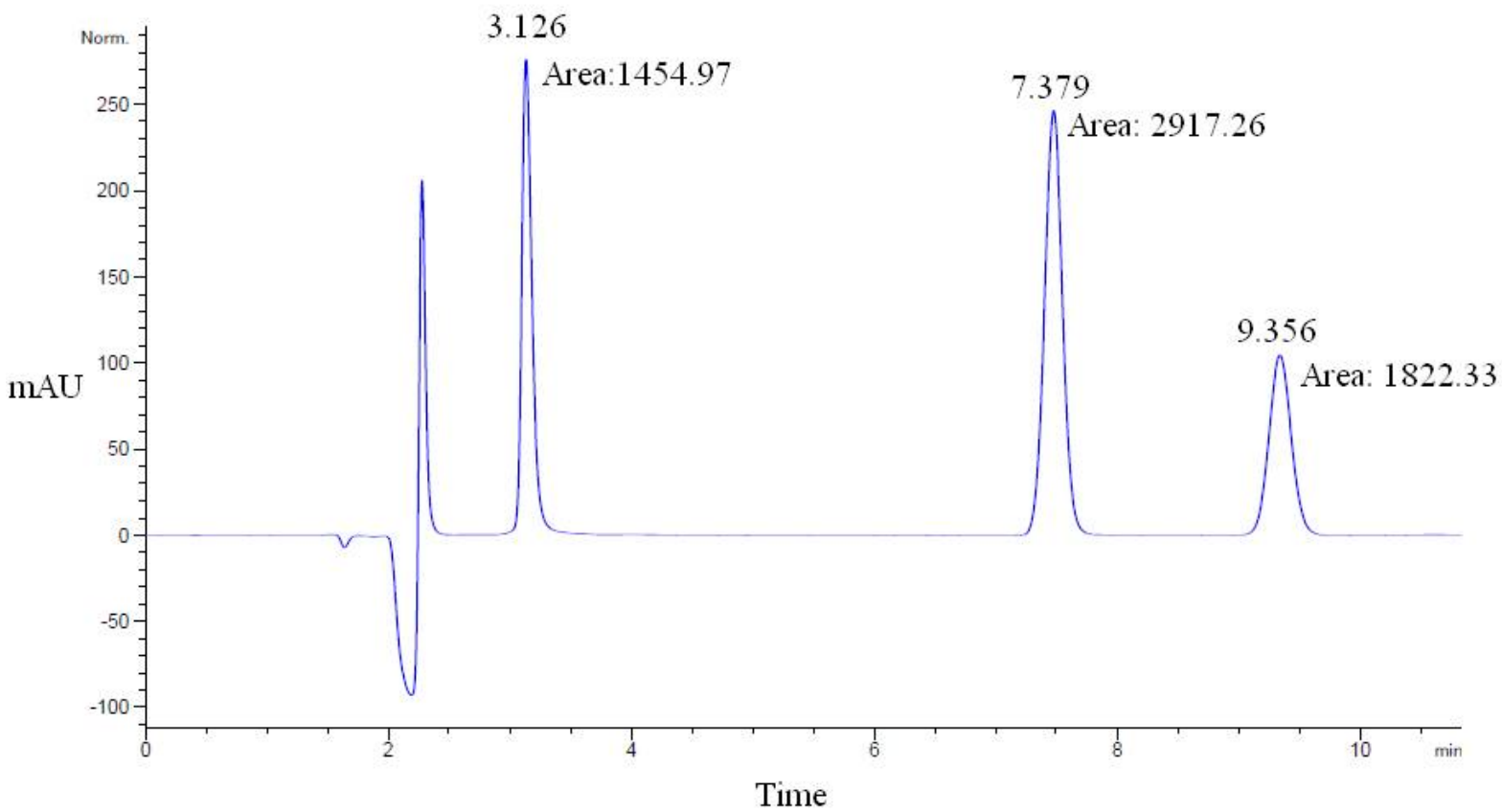

Fig 1: Chromatograms of a standard solution containing sodium benzoate, potassium sorbate and also caffeine. 


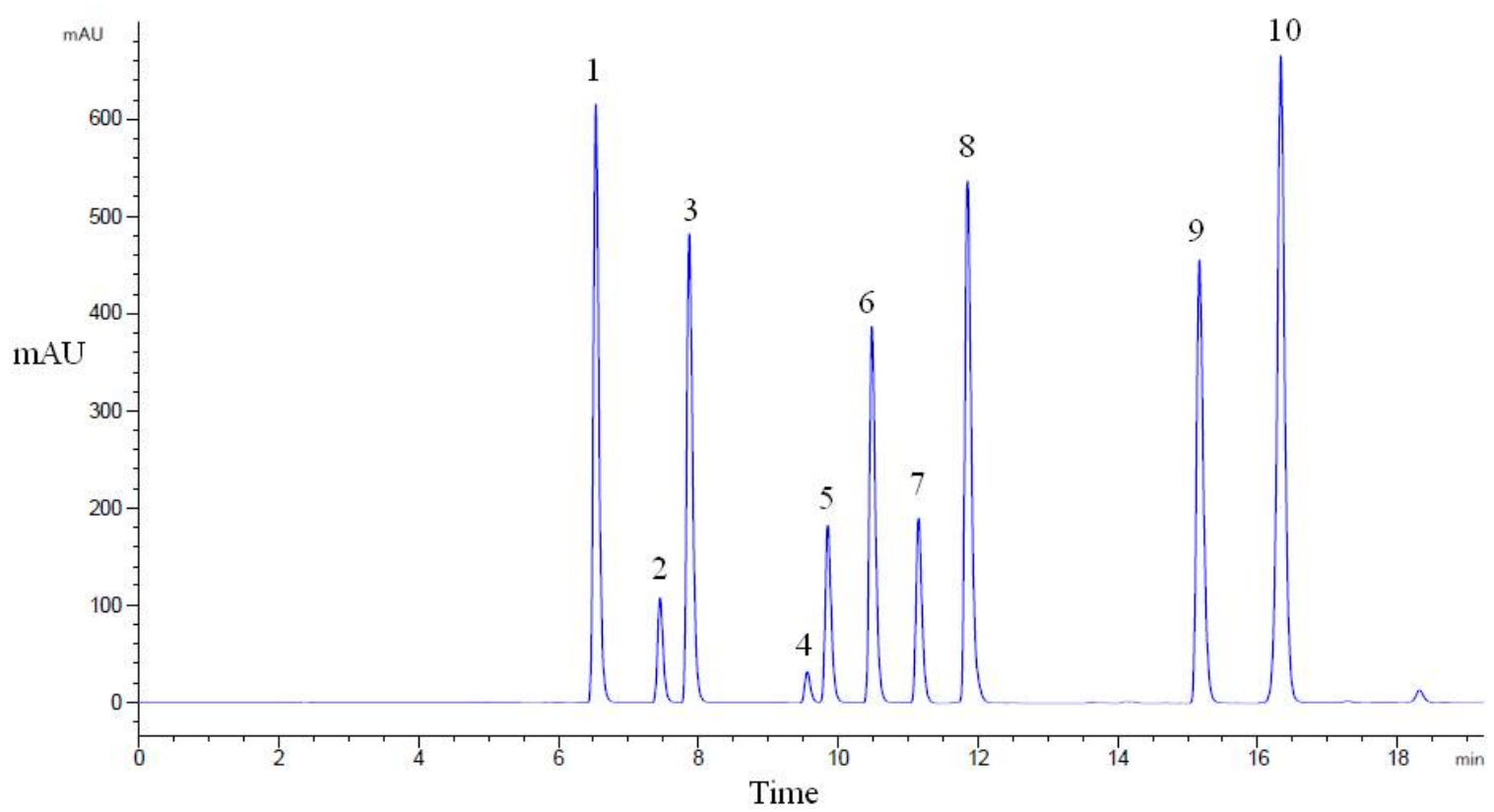

Fig 2: Resolution of chromatograms of synthetic dyes. 1 - Tartrazine; 2 - Quinoline yellow 1; 3 - Indigo carmine; 4 - Quinoline yellow 2; 5 - Ponceau 4R; 6 - Sunset yellow; 7 - Quinoline yellow 3; 8 - Allura red AC; 9 Carmozine; 10 - Brilliant blue

\section{DISCUSSION}

Additives perform a variety of useful functions in foods that consumers often take for granted. Some additives could be eliminated if we were willing to grow our own food, harvest and grind it, spend many hours cooking and canning, or accept increased risks of food spoilage. Iranian
National Standards [15] have some stringent rules for regulating the use of food additives. The level of sodium benzoate and potassium sorbate in Iranian standard (6693) [15] is 150 and 500 ppm, respectively. Therefore, based on the achieved results, $26.66 \%$ of samples had higher sodium benzoate but all samples were in the range of sorbate.

Table 2: Sodium benzoate and potassium sorbate concentrations (ppm) in different brands of sports-drink

\begin{tabular}{|c|c|c|c|c|}
\hline \multirow[b]{2}{*}{ Brand } & \multicolumn{2}{|c|}{$\begin{array}{l}\text { Sodium benzoate } \\
\end{array}$} & \multicolumn{2}{|c|}{ Potassium sorbate } \\
\hline & Mean \pm SD & Range & Mean \pm SD & Range \\
\hline $\mathrm{A}$ & $24.77 \pm 0.93$ & $24.25-26.18$ & 0 & 0 \\
\hline B & $12.50 \pm 16.67$ & $24.28-33.35$ & 0 & 0 \\
\hline C & $21.76 \pm 2.20$ & $18.66-23.35$ & 0 & 0 \\
\hline D & $18.19 \pm 1.91$ & $16.08-21.09$ & 0 & 0 \\
\hline $\mathrm{E}$ & 0 & 0 & 0 & 0 \\
\hline $\mathrm{F}$ & 0 & 0 & $35.01 \pm 4.22$ & 31.04-39.71 \\
\hline G & $28.41 \pm 5.03$ & $23.98-36.37$ & 0 & 0 \\
\hline $\mathrm{H}$ & 0 & 0 & 0 & 0 \\
\hline I & 0 & 0 & 0 & 0 \\
\hline $\mathrm{J}$ & 0 & 0 & 0 & 0 \\
\hline $\mathrm{K}$ & 0 & 0 & 0 & 0 \\
\hline L & 0 & 0 & 0 & 0 \\
\hline M & $242.34 \pm 24.83$ & $202.52-285.46$ & $53.26 \pm 36.71$ & $0-78.85$ \\
\hline $\mathrm{N}$ & $231.07 \pm 23.76$ & 204.51-257.86 & $96.38 \pm 38.56$ & $62.28-139.92$ \\
\hline $\mathrm{O}$ & $250.24 \pm 36.29$ & $226.26-304.29$ & $15.89 \pm 31.79$ & $0-63.59$ \\
\hline $\mathrm{P}$ & $251.50 \pm 18.69$ & $226.91-269.30$ & $66.38 \pm 41.10$ & $0-108.31$ \\
\hline Q & $144.99 \pm 77.02$ & $17.75-218.55$ & $28.80 \pm 29.51$ & $0-66.61$ \\
\hline $\mathrm{R}$ & $138.43 \pm 17.74$ & $123.24-150.93$ & 0 & 0 \\
\hline S & $163.14 \pm 18.40$ & $131.99-178.51$ & 0 & 0 \\
\hline $\mathrm{T}$ & $105.18 \pm 6.62$ & $94.30-111.86$ & 0 & 0 \\
\hline U & $95.66 \pm 109.51$ & $18.23-173.10$ & 0 & 0 \\
\hline
\end{tabular}


Table 3: Caffeine and color concentrations (ppm) in different brands of sports-drink

\begin{tabular}{lccccc}
\hline & \multicolumn{2}{c}{ Caffeine } & & \multicolumn{2}{c}{ Color } \\
\cline { 2 - 3 } \cline { 5 - 6 } Brand & Mean \pm SD & Range & Color Type & Mean \pm SD & Range \\
\hline A & $345.21 \pm 114.24$ & $174.45-389.60$ & & 0 & 0 \\
B & $443.87 \pm 36.75$ & $403.21-496.36$ & Brilliant Blue & $32.13 \pm 3.78$ & $27.37-36.48$ \\
C & $354.72 \pm 117.98$ & $179.34-431$ & Allura Red & $49.87 \pm 12.72$ & $68.84-42.54$ \\
D & $471.42 \pm 16.57$ & $452.46-486.96$ & & 0 & 0 \\
E & $490.76 \pm 27.86$ & $460-526.43$ & & 0 & 0 \\
F & $446.3 \pm 23.93$ & $425.02-481.34$ & & 0 & 0 \\
G & $490.07 \pm 49.38$ & $425.45-549.46$ & & 0 & 0 \\
H & $459.82 \pm 19.87$ & $437.97-478.74$ & & 0 & 0 \\
I & $453.06 \pm 15.39$ & $426.76-463.31$ & & 0 & 0 \\
J & $441.25 \pm 15.45$ & $420.66-456.79$ & & 0 & 0 \\
K & $484.93 \pm 17.55$ & $465.02-511.57$ & & 0 & 0 \\
L & $464.85 \pm 15$ & $449.66-484.42$ & & 0 & 0 \\
M & $543.78 \pm 80.99$ & $448.26-624.28$ & Allura Red & $6.92 \pm 0.72$ & 0 \\
N & $506.21 \pm 35.65$ & $463.14-548.39$ & & 0 & 0 \\
O & $502.65 \pm 53.29$ & $467.16-579.93$ & & 0 & 0 \\
P & $502 \pm 49.07$ & $449.8-574.39$ & & 0 & 0 \\
Q & $607.32 \pm 135.33$ & $503.61-836.99$ & & 0 & 0 \\
R & $514.02 \pm 36.16$ & $499.39-572.56$ & & 0 & 0 \\
S & $293.48 \pm 14.33$ & $284.77-314.68$ & & & 0 \\
T & $547.72 \pm 223.68$ & $235.66-776.31$ & & & $14.54 \pm 0.52$ \\
U & $531.28 \pm 37.83$ & $504.53-558.04$ & Allura Red & & $14.92-14.17$ \\
\hline
\end{tabular}

For some foodstuff in the study by Mota et al [16], sorbic acid and/or benzoic acid were reported to range from not detected (n.d.) to 210 and n.d. to $153 \mathrm{mg} / \mathrm{L}$, respectively. All sample concentrations of these compounds were below the stipulated limit of $300 \mathrm{mg} / \mathrm{L}$ for sorbic acid alone or $150 \mathrm{mg} / \mathrm{L}$ for benzoic acid alone [16]. In the three different samples of commercial wines, only sorbic acid was detected below $200 \mathrm{mg} / \mathrm{L}$, which complied with the legislation for preservatives in wines [16]. In another related research which the benzoic and sorbic acids were in quince jam, all quince jams contained benzoic acid in concentrations ranging from 413.9.10.46 to $1501.4 .2 \mathrm{mg}$ of benzoic acid $/ \mathrm{kg}$ [17]. In another study, it was shown that the amounts of benzoic and sorbic acid in jam were $639 \mathrm{mg} / \mathrm{kg}$ and $789 \mathrm{mg} / \mathrm{kg}$, respectively. Furthermore, the benzoic acid content of five of jam samples in Ferreira et al was above the legal limits of $500 \mathrm{mg} / \mathrm{kg}$ in Portugal [17].

Although $300 \mathrm{mg} /$ day of caffeine consumption is considered generally safe [18], there is no rapid method to determine caffeine content of sportsdrinks. In this study, the caffeine determination in samples was in the range of $345.21-543.78$ ppm in Iranian sports-drink samples. However, based on the results, other imported brands range was $293.40-607.33 \mathrm{ppm}$. Therefore, it must be asserted that caffeine amount in all samples was higher than the standard limitation of Iran (150 ppm) [15]. The lowest level of caffeine was detected in the soft drink, Coca Cola $(43.71 \pm 0.55)$, while the energy drinks showed the highest level of caffeine (58.31 \pm
$0.35 \mathrm{ppm})$. The range of caffeine content in the carbonated soft drinks group is between 43.71 and $45.83 \mathrm{ppm}$; while in it is from 47.56 to 58.31 ppm in the energy drink samples [19]. The mean caffeine content of carbonated soft drink was lower (44.52 ppm) than in the energy drinks (52.24 ppm. It was also observed that the caffeine level of the diet Cola $(45.83 \pm 1.05)$ was slightly higher compared to the regular cola drinks (Pepsi cola and Coca - cola). This is in agreement with previous work reported by Ali et al [20].

Food color additives are limited currently and only seven synthetic colors are permitted under these regulations. Color additives are used in foods for many reasons: to off-set color loss due to exposure to light, air, temperature extremes, moisture and storage conditions; to correct natural variations in colors; to enhance colors that occur naturally; and to provide color to colorless and "fun" foods. In the current study, all studied colors were not present in the sports drinks, but Brilliant blue and Allura Red were detected. In contrast to other countries, Ponceau $4 \mathrm{R}$ is prohibited in USA and Norway. Brilliant Blue is prohibited in many European countries. Tartrazine is also forbidden in the USA and Austria [11]. Based on the Iranian standard [15], there was no approved limits for sports drinks. Therefore, based on the achieved results, it seems that approved standards need to be revised both in terms of color type and related quantitative limitations made, regarding further risk assessments. 


\section{CONCLUSION}

HPLC provides a suitable method for the detection of caffeine, sodium benzoate and potassium sorbate at very low concentrations in sports drinks. It can separate both preservatives at one wavelength in $<10 \mathrm{~min}$ and involves minimal sample preparation. The content of potassium sorbate was below legal limits. Noncompliance with legal limits was only encountered for sodium benzoate and synthetic colors in some samples.

\section{ACKNOWLEDGEMENT}

This work was supported by a grant from Tehran University of Medical Sciences (no. 91-01-3317143).

\section{REFERENCES}

1. Aranda M, Morlock G. Simultaneous determination of riboflavin, pyridoxine, nicotinamide, caffeine and taurine in energy drinks by planar chromatography-multiple detection with confirmation by electrospray ionization mass spectrometry. J Chromatogr A 2006; 1131: 253260.

2. Barone J, Roberts H. Caffeine consumption. Food Chem Toxicol 1996; 34: 119-129.

3. Dong C, Wang W. Headspace solid-phase microextraction applied to the simultaneous determination of sorbic and benzoic acids in beverages. Anal Chim Acta 2006; 562: 23-29.

4. Techakriengkrai I, Surakarnkul R. Analysis of benzoic acid and sorbic acid in Thai rice wines and distillates by solid-phase sorbent extraction and high-performance liquid chromatography. J Food Compos Anal 2007; 20 : 220-225.

5. Wen $Y$, Wang $Y$, Feng $Y Q$. A simple and rapid method for simultaneous determination of benzoic and sorbic acids in food using in-tube solid-phase microextraction coupled with high-performance liquid chromatography. Anal bioanal chem 2007; 388: 1779-1787.

6. Koyuncu N, Uylaşer V. Determination of benzoic and sorbic acid in turkish food using high-performance liquid chromatography. J Food Process Pres 2009; 33: 361369.

7. Esfandiari Z, Badiey M, Mahmoodian P, Sarhang-pour R, Yazdani E, Mirlohi M. Simultaneous Determination of Sodium Benzoate, Potassium Sorbate and Natamycin Content in Iranian Yoghurt Drink (Doogh) and the Associated Risk of Their Intake through Doogh Consumption. Iran J Public Health 2013; 42: 915-920.
8. Costa AC, Perfeito Lda S, Tavares MF, Micke GA. Determination of sorbate and benzoate in beverage samples by capillary electrophoresis-Optimization of the method with inspection of ionic mobilities. J Chromatogr A 2008; 1204: 123-127.

9. Hajimahmoodi $M$, Oveisi MR, Sadeghi $N$, Jannat $B$, Nilfroush E. Simultaneous determination of Carmoisine and Ponceau 4R. Food Anal Method 2008; 1: 214-219.

10. Tavakoli M, Shemirani F, Hajimahmoodi M. Magnetic mixed hemimicelles solid-phase extraction of three food colorants from real samples. Food Anal Method 2014; 7: 100-108.

11. Hajimahmoodi M, Afsharimanesh M, Moghaddam G, Sadeghi N, Oveisi MR, Jannat B, Pirhadi E, Zamani Mazdeh F, Kanan H. Determination of eight synthetic dyes in foodstuffs by green liquid chromatography. Food Addit Contam A 2013; 30: 780-785.

12. Khera K, Munro IC, Radomski JL. A review of the specifications and toxicity of synthetic food colors permitted in Canada. CRC Cr Rev Toxicol 1979; 6: 81133.

13. Khanavi M, Hajimahmoodi $M$, Ranjbar AM, Oveisi MR, Shams Ardekani MR, Mogaddam G. Development of a green chromatographic method for simultaneous determination of food colorants. Food Anal Method 2012; 5: 408-415.

14. Yoshioka N, Ichihashi K. Determination of 40 synthetic food colors in drinks and candies by high-performance liquid chromatography using a short column with photodiode array detection. Talanta 2008; 74: 14081413.

15. Iranian Standard. http://isiri.ir/.

16. Mota FJM, Ferreira IM, Cunha SC, Oliveira MB. Optimisation of extraction procedures for analysis of benzoic and sorbic acids in foodstuffs. Food chem 2003; 82: 469-473.

17. Ferreira IM, Mendes $E$, Brito $P$, Ferreira MA. Simultaneous determination of benzoic and sorbic acids in quince jam by HPLC. Food Res Int 2000; 33: 113117.

18. Saad B, Bari MF, Saleh MI, Ahmad K, Talib MK. Simultaneous determination of preservatives (benzoic acid, sorbic acid, methylparaben and propylparaben) in foodstuffs using high-performance liquid chromatography. J Chromatogr A 2005; 1073: 393-397.

19. Amos-Tautua W, Diepreye E. Ultra-violet Spectrophotometric Determination of Caffeine in Soft and Energy Drinks Available in Yenagoa, Nigeria. Adv J Food Sci Technol 2014; 6: 155-158.

20. Ali MM, Eisa M, Taha MI, Zakaria BA, Elbashir AA. Determination of Caffeine in Some Sudanese Beverages by High Performance Liquid Chromatography. PJN 2012; 11: 336. 